\title{
COMPARATIVE STUDY BETWEEN: TIME OF USING AND REAL- TIME PRICING USING FUZZY TECHNIQUE
}

\begin{abstract}
Demand-side management (DSM) programs in the industrial sector appear to be economically feasible due to the large controllable loads and relatively low costs per control point. Innovative electricity tariffs provide one of the most important DSM alternatives. Because real-time pricing (RTP) is considered as management option which reflects the real cost of generating electricity to the end user, the electricity cost saving potential of RTP through demand management is presented in this paper. These variables include the installed power consumption capacity of the plant, the plant's spare energy consumption capacity, and terms that describe the structure of the RTP tariff.

Time of using (TOU) pricing compared with (RTP) is presented, can either be applied as load management (LM) program or as incentive to drive the economics and the motivation to implement other types of LM programs. TOU pricing also can be taken as a way for consumers to adjust the electricity consumption among different time axis in accordance with the cost of electricity.

In the present paper, we proposed the fully arithmetic fuzzy operations method which is applied where all the parameters and variables are characterized by triangular fuzzy numbers. A comparison of Fuzzy arithmetic operations and ordinary operations is given ${ }^{[1]}$.
\end{abstract}

Ali Hassan Ibrahim Mansour ${ }^{1}$ and A.S. Ahmed $^{2}$,

${ }^{1}$ Faculty of engineering Al-Azhar University- Qena

${ }^{2}$ Petroleum Pipeline Co., Cairo - Egypt

\section{INTRODUCTION}

Since the introduction of DSM in the 1970's, load management projects mainly concentrated on residential loads. Some of the projects have resulted in a fair profitability, but many of the programs have not succeeded in achieving the established objectives, mainly due to the size of load per control point. Bjork ${ }^{[2]}$ stated that it is likely that applications with low cost per controlled load may be found in industry, where the controllable load per control point is relatively large. Flory et al. ${ }^{[3]}$ reported that at many utilities $2-10 \%$ of the industrial customers account for at least $80 \%$ of the electricity usage, which emphasises the economic feasibility of DSM programs in the industrial sector.

Although time of use (TOU) pricing represented a significant step towards efficient electricity pricing, there is a growing recognition that dynamic tariff forms can be more efficient. Dynamic pricing broadly encompasses tariff structures that have one or more elements which can be calculated and posted close to the time of applicability ${ }^{[5]}$. This definition embraces several concepts developed in the pricing literature, such as real-time (spot) pricing and other forms of "innovative" rates. The theory behind this pricing strategy is well documented ${ }^{[6]}$.

By reflecting the "real" cost of electricity to the consumer through variable prices for specificgenerally one hour-time periods, the utility provides the consumer with the information necessary to make economically sound load management decisions. Benefits of sport pricing for a customer are shown to increase with ${ }^{[4]}$ :

- The magnitude of price changes over time ;

- The magnitude of the customer's storage capacity;

- The amount of his peak production capacity. 
These observation were made in ${ }^{[4]}$ by means of a linear program (LP) based optimization algorithm. The purpose of this paper is to add more insight into the electricity cost saving potential of real-time pricing (RTP) through intelligent demand management. The analytical approach as illustrated, will enable utilities and industrial end user of electricity to acquire a better knowledge of the benefits that RTP can offer.

One of these benefits, i.e. the electricity cost saving potential. It will be presented as a function of variables that describe the structure of the real-time prices, as well as the configuration of the industrial plant, which includes the spare energy consumption capacity of the end user and the installed power consumption capacity.

A fuzzy number $A=\langle a, b, c\rangle$ on $\mathrm{R}$ is said to be triangular fuzzy number, if its membership function is given as follows:

$$
\tilde{a}(x)=\left\{\begin{array}{ll}
\frac{x-a}{b-a}, & x \in[a, b] \\
\frac{x-c}{b-c}, & x \in[b, c] \\
0, & \text { O.w. }
\end{array}\right\}
$$

We denote a triangular fuzzy number $\tilde{a}$ by three real numbers $\mathrm{s}, 1$ and $\mathrm{r}$ as $\tilde{a}=\langle a, b, c\rangle$ whose meaning are defined. We also denote the set of all triangular fuzzy number with $\mathrm{F}(\mathrm{R})$. Arithmetic operations between two triangular fuzzy number is used ${ }^{[1]}$.

A load scheduling strategy which may result in minimum electricity costs to the end user, is presented. The feasibility of the strategy depends on certain assumptions, which will be given. The mathematical modelling of the price duration curve (hourly marginal rate duration curve) is introduced in section III. In section IV mathematical expressions of the electricity costs of an end user under one-part RTP tariff structures are derived. Section V presents the mathematical expression of the electricity cost saving potential under RTP.

\section{2.. OPTIMAL LOAD SCHEDULING STRATEGY}

An industrial end user of electricity that is able to curtail processes on short notice in order to respond to hourly varying energy tariffs, may be able to benefit from RTP. By assuming:

1. That the plant has adequate installed storage capacity or spare energy consumption capacity;

2. That no losses due to load scheduling occur;

3. That the demand levels of the individual controllable processes in the plant can be controlled, without constraints, between a maximum level $\mathrm{P}_{\max }$ and a minimum level $\mathrm{P}_{\min }$;

4. That each individual controllable process has a certain constant base power (or power loss component) $\mathrm{P}_{\text {loss }}$ that does not contribute to any production;

5. That the same production target should be reached under controlled and uncontrolled conditions within the same time horizon of $H$ hours;

6. That an amount of $E K W h$ of electrical energy is required to produce the required production target;

7. That a one -part RTP structure is considered without a fixed cost component (thus only marginal rates apply).

The total electricity costs $E C$ (in P.T.) over $H$ hours of production can be given as:

$$
\mathrm{EC}=\mathrm{x}_{1} \mathrm{hmr}_{1}+\mathrm{x}_{2} \mathrm{hmr}_{2}+\ldots . . \mathrm{x}_{H} \mathrm{hmr}_{H}
$$


where $\mathrm{x}_{i}$ represents the total hourly power consumption (actually the average of hourly power) of the processes in hour $i$, while $\mathrm{hmr}_{i}$, is the hourly marginal rate (in P.T/kWh) of the RTP tariff structure in hour $i$. the aim is to find the values of $\mathrm{x}_{i}$ which will minimize the objective function in (1) subject to the following set of linear constraints:-

and

$$
\begin{aligned}
& \left(\mathrm{x}_{1}-\mathrm{b}\right)+\left(\mathrm{x}_{2}-\mathrm{b}\right)+\ldots \ldots+\left(\mathrm{x}_{\mathrm{H}}-\mathrm{b}\right)=\mathrm{E} \\
& \mathrm{x}_{1+} \mathrm{x}_{2}+\ldots . .+\mathrm{x}_{\mathrm{H}}=\mathrm{E}+\mathrm{b} . \mathrm{H}
\end{aligned}
$$

$$
\mathrm{P}_{\min } \leq \mathrm{x}_{i} \leq \mathrm{p}_{\max } \mathrm{i}=1,2,3 \ldots \ldots \ldots ., \mathrm{H}
$$

Where $b$ is the total hourly non- productive power (or base power) which is assumed to be constant over time. By means of an upper -bounding dual linear programming algorithm ${ }^{[7]}$ it has been shown that the minimum electricity costs will be obtained if the processes' power demand levels demand levels are either at $P_{\min }$ when hourly rates are high, and at $P_{\max }$ when the hourly rates are low.

For TOU pricing the energy cost from previous study, a own-and cross-price elasticities mode was developed from a transcendental logarithmic (translog) cost function ${ }^{[10]}$.

$\ln E C=a+\sum_{i} \alpha_{i} \ln p_{i}+\frac{1}{2} \sum_{i} \sum_{j} \beta_{i j} \ln p_{i} \ln p_{j}+\sum_{i} \gamma_{i} \ln p_{i} \ln E+\phi \ln E+\sum_{i} \pi_{i} \ln p_{i} \ln C D D$

$+\delta \ln C D D$

For RTP there exists a certain hourly marginal rate cut- off value, $H M R_{c u t}$, which will provide the threshold price above which the power levels should be shut down to $P_{\min }$ and below which the power levels should be set at $\mathrm{P}_{\max }$.

An hourly marginal rate duration curve (HMRDC) can be used to graphically display this concept and to form the basis of the mathematical expressions which will follow. Fig.(1) "derived from load duration curve of average unified power system generation for Arab Republic of Egypt over the year (97/98)", Illustrates actual discrete hourly marginal rate (hmr) values for $H$ hours, sorted from the highest to lowest value to form the discrete HMRDC. The corresponding power demand levels according to the proposed optimum scheduling strategy are shown together with cut-off hour, $\mathrm{H}_{\text {cut }}$, where "transition" occurs between the $\mathrm{P}_{\min }$ and $\mathrm{P}_{\max }$ levels. When this value of $\mathrm{H}_{\text {cut }}$ is projected upwared to the HMRDC, the value of $\mathrm{HMR}_{\text {cut }}$ can be read from the duration curve.

\section{MODELLING OF THE HMRDC}

The load duration curve (LDC) offers a tool by which DSM impacts can be quantified into power system planning and operation. Models of the LDC provide one of the most important tools in the analysis of electric power systems. There are several methods attempting to express the LDC mathematically and a recent report ${ }^{[8]}$ presented an analytical approach which appears to give credible results.

Based on this analytical method, a model of the HMRDC is derived ${ }^{[9]}$. With this model the hourly marginal rates $h m r(h)$ are described in terms of four principal Parameters of the HMRDC, $i$. $e$. the peak hour marginal rate $P$, the base hour marginal rate $\mathrm{B}$, the time horizon $\mathrm{H}$. and the average value of the hourly marginal rates over $\mathrm{H}$ hours, $h m r_{\text {ave }}$. The last term is directly proportional to the area underneath the HMRDC.

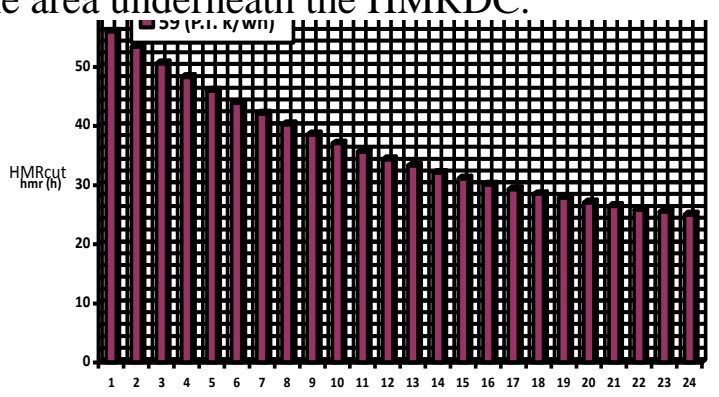

hours (h)

${ }^{B}$ Fig. (1) HMRDC and corresponding optimal power demand levels 
The resulting mathematical expression is given as ${ }^{[9]}$ :

$$
h m r(h)=B+(P-B)\left(1-\frac{h}{H}\right) \text { exp } \frac{c . h}{H} \quad[P . T . / k W h]
$$

where $\mathrm{C}$ is the curve shape factor. The curve will have a concave shape when $\mathrm{C}<0$ (like the one shown in (Fig.1), a convex shape when $\mathrm{C}>0$, and a linear shape with a negative slope when $\mathrm{C}=0$. The value of $\mathrm{C}$ is given as ${ }^{[9]}$ :

$$
C=\sum_{n=1}^{7} R_{n}\left[\frac{h m r_{a v e}-B}{P-B}-\frac{1}{2}\right] n
$$

Where the values of $R_{n}$ are the same as that derived in the analytical model of an inverse load duration curve. The model represents the inverted load duration curve (ILDC) directly as a function of peak load (p), base load (B) and total energy (E). This is a more accurate model of the load shape for use in planning and operation activities. Especially after incorporating demand side management alternatives. The model is ${ }^{[8]}$ the values of $R_{n}$ :-

$$
\begin{aligned}
& R_{1}=\frac{1}{a_{1}} \\
& R_{2}=\frac{-a_{2}}{a_{1}^{3}} \\
& R_{3}=\frac{1}{a_{1}^{5}}\left(2 a_{2}^{2}-a_{1} a_{3}\right) \\
& R_{4}=\frac{1}{a_{1}^{7}}\left(5 a_{1} a_{2} a_{3}-a_{1}^{2} a_{4}-5 a_{2}^{3}\right) \\
& R_{5}=\frac{1}{a_{1}^{9}}\left(6 a_{1}^{2} a_{2} a_{4}+3 a_{1}^{2} a_{3}^{2}+14 a_{2}^{4}-a_{1}^{3} a_{5}-21 a_{1} a_{2}^{2} a_{3}\right) \\
& R_{6}=\frac{1}{a_{1}^{11}}\left(7 a_{1}^{3} a_{2} a_{5}+7 a_{1}^{3} a_{3} a_{4}+84 a_{1} a_{2}^{3} a_{3}-a_{1}^{4} a_{6}-28 a_{1}{ }^{2} a_{2}{ }^{2} a_{4}-28 a_{1}{ }^{2} a_{2} a_{3}^{3}-42 a_{2}{ }^{5}\right) \\
& R_{7}=\frac{1}{a_{1}^{13}}\left(8 a_{1}^{4} a_{2} a_{6}+8 a_{1}{ }^{4} a_{3} a_{5}+4 a_{1}^{4} a_{4}{ }^{2}+120 a_{1}{ }^{2} a_{2}{ }^{3} a_{4}+132 a_{2}^{6}\right. \\
& \left.+180 a_{1}^{2} a_{2}^{2} a_{3}^{2}-a_{1}{ }^{5} a_{7}-36 a_{1}^{3} a_{2}^{2} a_{5}-72 a_{1}^{3} a_{2} a_{3} a_{4}-12 a_{1}^{3} a_{3}^{3}-330 a_{1} a_{2}^{4} a_{3}\right) \\
& a_{n}=\frac{1}{(n+2)^{!}} \quad n=1,2,3, \ldots \ldots ., 7
\end{aligned}
$$

For comparing method of RTP and TOU pricing. The TOU pricing $\mathrm{p}_{i}$ at period $i$ can be solved as ${ }^{[10]}:-$

$$
p_{i}=\frac{M C i}{W i\left[1+\frac{1}{\eta_{i i}}+\sum_{j=1, j \neq n}^{n}\left[\frac{1}{S_{i j}} \cdot \frac{1}{\eta_{i j}}\right]\right]}
$$

Fig. (1): Illustrates an example for LDC of ARE year (97/98) where

$\mathrm{P}=59 \mathrm{P} . \mathrm{T} / \mathrm{k} \mathrm{Wh}, B=25 \mathrm{P} . \mathrm{T} / \mathrm{k} \mathrm{Wh}, H=24$ hours,$h m r_{\mathrm{ave}}=36.87$ 
P.T $/ \mathrm{K}$ Wh, and $\mathrm{C}=-1.19$.

By inspection of fig. (1), the total energy E required (in $\mathrm{kWh}$ ) within $\mathrm{H}$ hours to reach the production target is given as:

$$
\mathrm{E}=\mathrm{H} .\left(P_{\max }-P_{\text {loss }}\right)-\mathrm{H}_{\text {Cut }}\left(P_{\max -} P_{\min }\right)
$$

From which $H_{\text {cut }}$ is derived as:

$$
H_{c n t}=\frac{H\left(P_{\max -} P_{l o s}\right)-E}{\left(P_{\max }-P_{\min }\right)}=\frac{Q}{\left(P_{\max }-P_{\min }\right)}
$$

Where $Q$ is the total spare energy consumption capacity (in $\mathrm{KWh}$ ) of the controllable processes. If no load scheduling is applied, it is assumed that the plant has to operate on a constant power demand level of $P_{\text {avg }}$ to produce the same production target in $\mathrm{H}$ hours. This value will be between $P_{\max }$ and $P_{\min }$ with the same area $E$ underneath the power curve

$$
\begin{aligned}
P_{\text {avg }}=P_{\text {loss }}+\frac{E}{H}=P_{\text {loss }}+ & \frac{H\left(P_{\max }-P_{\text {loss }}\right)-Q}{H} \\
& =P_{\max }-\frac{Q}{H} \quad(k W)
\end{aligned}
$$

\section{4.. ELECTRICITY COSTS TO THE END USER WITHOUT LOAD SCHEDULING}

The basic structure of a one-part RTP consists of marginal energy rates applicable to the hourly energy consumption of the end user. If one considers no load scheduling operation, and assumes that the plant operates at a constant power demand level of $\mathrm{P}_{\text {avg }}$ to produce the production target, an expression for the electricity costs $\mathrm{EC}_{\mathrm{nls}}$ (in P.T.) is given in (12) by using (5) and (11) (the footnote $n l s$ denotes no load scheduling). The non-linear dependency of the electricity costs to the parameters of the hourly marginal rates is evident from (12), while it is linearly on the spare energy consumption capacity $Q$ of the plant.

$$
E C_{n l s}=\left[\frac{H \cdot P_{\max }-Q}{C^{2}}\right]\left[B \cdot C^{2}+(P-B)\left(\exp ^{C}-C-1\right)\right]
$$

Energy cost for TOU pricing we use equations $(8,4)$.

\section{ELECTRICITY COST SAVING POTENTIAL:}

When the end user is applying optimum load scheduling operation as proposed earlier, an expression for the electricity costs under load scheduling operation, $\mathrm{EC}_{\mathrm{ls}}$ (in P.T.) is given in (13) (where the footnote ls denotes load scheduling).

$$
\begin{aligned}
& E C_{l s}=\frac{P_{\max }}{C^{2}}\left[B \cdot C^{2} \cdot H+H \cdot(P-B) \exp ^{C}\right]- \\
& \frac{P_{\min }}{C^{2}}\left[H(P-B)(C+1]+\left[\frac{P_{\max }-P_{\min }}{C^{2}}\right] x\right. \\
& {\left[(p-B)\left(C . H_{c u t}-C . H-H\right) \exp \frac{C . H_{c u t}}{H}-B . C^{2} . H_{c u t}\right]}
\end{aligned}
$$

T.O.U pricing to be offered to the customers with load management programs at period $\mathrm{i}$ is derived as ${ }^{[10]}$ : 


$$
p^{\prime}{ }_{i}=\frac{M C i}{W i\left[1+\frac{1}{\eta^{\prime}{ }_{i i}}+\sum_{j=1, j \neq n}^{n}\left[\frac{1}{S_{i j}^{\prime}} \cdot \frac{1}{\eta^{\prime}{ }_{i j}}\right]\right]}
$$

The potential electricity cost savings ECS (in P.T.) to the end user are the difference in electricity costs between scheduled and unscheduled operation (RTP).

$$
\mathrm{ECS}=\mathrm{EC}_{\mathrm{nls}}-\mathrm{EC}_{\mathrm{ls}}
$$

The expression for the percentage electricity cost savings \% ECS is given as:

$$
\% E C S=100 . \frac{E C S}{E C_{n l s}}=100\left[1-\frac{E C_{l s}}{E C_{n l s}}\right] \quad[\%]
$$

By substituting (12) and (13) into(15) the following results:

$$
\begin{aligned}
& E C S=\left[\frac{P_{\max }-P_{\min }}{C^{2}}\right]\left\{\begin{array}{c}
\left.(P-B)\left[\begin{array}{c}
H(C+1)\left(\exp \frac{C \cdot H_{C_{u t}}}{H}-1\right) \\
\ldots-H_{c u t} \cdot C \cdot \exp \frac{C \cdot H_{C u t}}{H}
\end{array}\right]\right\} \\
\ldots+B \cdot H_{c u t} \cdot C^{2}
\end{array}\right\} \\
& -\frac{Q}{C^{2}}\left[B \cdot C^{2}+(P-B)\left(\exp ^{C}-C-1\right)\right] \\
& {[P . T .]}
\end{aligned}
$$

The maximum installed energy consumption capacity $\mathrm{E}_{\max }$ available to produce products in $H$ hours is:

$\mathrm{E}_{\max }=\mathrm{H} .\left(\mathrm{P}_{\max }-\mathrm{P}_{\text {loss }}\right) \quad[\mathrm{KWh}]$

While the maximum spare energy consumption capacity $\mathrm{Q}_{\max }$ over that period is:

$\mathrm{Q}_{\max }=\mathrm{H} .\left(\mathrm{P}_{\max }-\mathrm{P}_{\min }\right)$

[KWh]

From (17) and (18):

$\frac{Q_{\max }}{E_{\max }}=\left[\frac{P_{\max }-P_{\min }}{P_{\max }-P_{\text {loss }}}\right]$

\section{6.. RESULTS}

\section{Case study:}

\begin{tabular}{|c|c|c|c|c|c|c|c|c|}
\hline \multicolumn{9}{|c|}{ Table [1] RTP pricing } \\
\hline Year & $\begin{array}{c}\text { Peak } \\
\text { pricing "P" } \\
{[\text { P.T./kwh] }}\end{array}$ & $\begin{array}{c}\text { Base } \\
\text { pricing"B" } \\
{[\text { P.T./kwh] }}\end{array}$ & $\begin{array}{c}H m r_{\text {ave. }} \\
\text { [P.T./kwh] }\end{array}$ & $\mathrm{C}$ & $\begin{array}{c}\text { EC } \\
\text { [L.E./day] }\end{array}$ & $\begin{array}{c}\mathrm{EC}_{\mathrm{nls}} \\
\text { [L.E./day] }\end{array}$ & $\begin{array}{c}\mathrm{EC}_{\mathrm{ls}} \\
\text { [L.E./day] }\end{array}$ & $\begin{array}{c}\text { ECS } \\
\text { [L.E./day] }\end{array}$ \\
\hline 1986 & 36.5 & 15 & 22.625 & -1.1622 & 21387066 & 6103.9 & 5793 & 310.9 \\
\hline $91 / 92$ & 46 & 19 & 28.75 & -4.224 & 31573189 & 8210 & 8005 & 205 \\
\hline $97 / 98$ & 59 & 25 & 36.87 & -1.19 & 66387350 & 12963.5 & 12304.3 & 659.2 \\
\hline
\end{tabular}

For an industrial Co. let $\mathrm{P}_{\max }=1300,1530,1700 \mathrm{KW}$ and $\mathrm{P}_{\min }=780,1225$ and $1000 \mathrm{KW}$,

\begin{tabular}{|c|c|c|c|c|c|c|c|}
\hline \multicolumn{8}{|c|}{ Table [2] TOU pricing } \\
\hline \multirow[t]{2}{*}{ Year } & \multicolumn{2}{|c|}{ Peak period } & \multicolumn{2}{|c|}{ Mid peak period } & \multicolumn{2}{|c|}{ Off peak period } & EC \\
\hline & $\begin{array}{c}\mathrm{P}_{1} \\
\text { [P.T./kwh] }\end{array}$ & $\begin{array}{c}\mathrm{Q}_{1} \\
{[\mathrm{Mwh}]}\end{array}$ & $\begin{array}{c}\mathrm{P}_{2} \\
\text { P.T./kwh }\end{array}$ & $\begin{array}{c}\mathrm{Q}_{2} \\
{[\mathrm{Mwh}]}\end{array}$ & $\begin{array}{c}\mathrm{P}_{3} \\
\text { P.T./kwh] }\end{array}$ & $\begin{array}{c}\mathrm{Q}_{3} \\
{[\mathrm{Mwh}]}\end{array}$ & Energy cost [L.E./day] \\
\hline 86 & 36.5 & 17839 & 21 & 35678 & 15 & 35678 & 1935531 \\
\hline $91 / 92$ & 46 & 24882 & 27 & 49764 & 19 & 49764 & 34337160 \\
\hline 97/98 & 59 & 34218.8 & 34 & 68437.6 & 25 & 68437.6 & 60567276 \\
\hline
\end{tabular}
$\mathrm{P}_{\text {loss }}=10 \%$ respectively for years $86,91 / 92$ and $97 / 98$, we will calculate $\mathrm{EC}_{\mathrm{nls}}, \mathrm{EC}_{\mathrm{ls}}$ and $\mathrm{ECS}$ for above.

\section{RESULTS:}




\begin{tabular}{|c|c|c|c|c|c|c|c|c|}
\hline \multicolumn{9}{|c|}{ Fuzzy Table [3] RTP pricing } \\
\hline Year & $\begin{array}{c}\text { Peak pricing } \\
\text { "P" } \\
\text { [P.T./kwh] }\end{array}$ & $\begin{array}{c}\text { Base } \\
\text { pricing"B" } \\
{[\text { P.T./kwh] }}\end{array}$ & $\begin{array}{c}H m r_{\text {ave. }} \\
\text { [P.T./kwh] }\end{array}$ & $\mathrm{C}$ & $\begin{array}{c}\text { EC } \\
{\left[10^{3} \text { L.E./day }\right]}\end{array}$ & $\begin{array}{c}\mathrm{EC}_{\mathrm{nls}} \\
\text { [L.E./day] }\end{array}$ & $\begin{array}{c}\mathrm{EC}_{\mathrm{ls}} \\
{[\text { L.E./day] }}\end{array}$ & $\begin{array}{c}\text { ECS } \\
\text { [L.E./day] }\end{array}$ \\
\hline 1986 & $(28,36.5,42)$ & $(10,15,22)$ & $(16.375,22.625,30)$ & -1.1622 & $\begin{array}{c}(10848,21345 \\
32293)\end{array}$ & $\begin{array}{l}(2985, \\
6109, \\
9802)\end{array}$ & $(2892,7968)$ & $(342,406)$ \\
\hline $91 / 92$ & $(40,46,52)$ & $(15,19,22)$ & $\begin{array}{c}(24.25,28.75 \\
33.25)\end{array}$ & -4.224 & $\begin{array}{c}(23506,31589 \\
39014.1)\end{array}$ & $\begin{array}{l}(4120, \\
8195, \\
1106)\end{array}$ & $(6349,9279)$ & $\begin{array}{l}(173.1, \\
326.5)\end{array}$ \\
\hline 97/98 & $(50,59,65)$ & $(18,25,32)$ & $(29.75,36.875,44)$ & -1.19 & $\begin{array}{l}(42541446, \\
66324805, \\
89064804)\end{array}$ & $\begin{array}{l}(7992, \\
12965, \\
18165)\end{array}$ & 12461,19322) & $(310,884)$ \\
\hline
\end{tabular}

\begin{tabular}{|c|c|c|c|c|c|c|c|}
\hline \multicolumn{8}{|c|}{ Fuzzy Table [4] TOU pricing } \\
\hline \multirow[t]{2}{*}{ Year } & \multicolumn{2}{|c|}{ Peak period } & \multicolumn{2}{|c|}{ Mid peak period } & \multicolumn{2}{|c|}{ Off peak period } & \multirow{2}{*}{\begin{tabular}{|c|}
$|c|$ \\
Energy cost [L.E./day] \\
Energy cost [L.E./day]
\end{tabular}} \\
\hline & $\begin{array}{c}\mathrm{P}_{1} \\
\text { [P.T./kwh }\end{array}$ & $\begin{array}{c}\mathrm{Q}_{1} \\
{[\mathrm{Mwh}]}\end{array}$ & $\begin{array}{c}\mathrm{P}_{2} \\
{[\text { P.T./kwh] }}\end{array}$ & $\begin{array}{c}\mathrm{Q}_{2} \\
{[\mathrm{Mwh}]}\end{array}$ & $\begin{array}{c}\mathrm{P}_{3} \\
{[\text { P.T./kwh] }}\end{array}$ & $\begin{array}{c}\mathrm{Q}_{3} \\
{[\mathrm{Mwh}]}\end{array}$ & \\
\hline 86 & $\begin{array}{c}(28,36.5 \\
42)\end{array}$ & $\begin{array}{c}(17356, \\
17836,18316)\end{array}$ & $\begin{array}{l}(15,21, \\
30)\end{array}$ & $\begin{array}{l}(34712, \\
35672, \\
36632)\end{array}$ & $(10,15,22)$ & $\begin{array}{l}(34712, \\
35672, \\
36632)\end{array}$ & $\begin{array}{c}(13537680,19352060, \\
26741360)\end{array}$ \\
\hline $91 / 92$ & $(40,46,52)$ & $\left|\begin{array}{c}(24409, \\
24892,25382)\end{array}\right|$ & $\begin{array}{c}(23,27, \\
32)\end{array}$ & $\begin{array}{l}48818, \\
49784, \\
50764)\end{array}$ & $(15,19,22)$ & $\begin{array}{l}48818, \\
49784, \\
50764)\end{array}$ & $\begin{array}{c}(28314440,34350960 \\
40611200)\end{array}$ \\
\hline $97 / 98$ & $\begin{array}{l}(50,59 \\
65)\end{array}$ & $\begin{array}{c}(33664, \\
34222,34786)\end{array}$ & $\begin{array}{c}(28,34 \\
42)\end{array}$ & $\begin{array}{l}67328, \\
68444, \\
69572)\end{array}$ & $(18,25,32)$ & $\begin{array}{l}67328, \\
68444, \\
69572)\end{array}$ & $\begin{array}{c}(47802880,60572940 \\
74094180)\end{array}$ \\
\hline
\end{tabular}

\section{CONCLUSION}

Based on a number of assumptions, an optimal load scheduling strategy was proposed to minimize the electricity costs of an industrial end user under one-part RTP "Preferred than TOU". A method was presented which may be used by an industrial end user to respond adequately to real-time electricity prices. With the aid of an hourly marginal rate duration curve the threshold value of the hourly marginal rates can be determined where the end user should control his loads.

For TOU pricing it is recommend that increasing the pricing difference between peak period and off- peak period so that better incentive could be provided to promote more indusial customers to participate LM programs so that system peak demand can be reduced.

\section{REFERENCES}

[1] Moumita Deb and P.K. De "optimal solution of a fully fuzzy linear fractional programming problem by using Graded Mean Integration representation- Method" application and applied mathematics: an international Journal Vol. 10, issue 1, [June, 2105], pp. 571-587.

[2] C.O. Bjork, Industrial Load management: Theory, practice and Simulations, Elsevier science publishers, Amsterdam, 1989.

[3] J. Flory, J. Peters, L. Vogt, K. Keating, and B. Hopkins, "Evaluating DSM: can an engineer count on it? A short note paper summarizing a panel decision, "IEEE Transactions on Power Systems, Vol. 9, no. 4, Nov. 1994, pp. 1752-1758.

[4] B. Daryanian, R.E. Bohn, and R.D. Tabors, "Optimal demand-side response to electricity spot prices for storage-type customers," IEEE transactions on Power Systems, Vol. 4, no. 3, Aug. 1989, pp. 897-903. 
[5] A.P. Sanghvi, "Flexible strategies for load/demand management using dynamic pricing", IEEE Transactions on Power Systems, Vol. 4, no. 1, Feb.1989, pp. 83-93.

[6] F.C. Schweppe, M.C. Caramanis, R.D. Tabors, and R.E. Bohn, Sport Pricing of Electricity, Kluwer Academic Publishers, Boston, USA, Edition 1, 1988.

[7] A.J. Wood, and B.F. Wollenberg, Power Generation, Operation, and Control, John Wiley and Sons, New York, 1984.

[8] S. Rahman, and Rinaldy, "An efficient load model for analyzing demand-side management impacts" IEEE Transactions on. Power Systems, Vol. 8, no. 3, Aug 1993, pp., 1219-1226.

[9] J.G. Roos, and I.E. lane, " Industrial power demand response analysis for one- part Real- time pricing", IEEE transactions on power systems, Vol. 13, No.1, Feb, 1998, pp. 159-164.

[10] J-N Sheen, C-S Chen, and J-K Yang, "time of use pricing for load management programs in Taiwan power company", IEEE transaction on power systems, Vol. 9, No.1, Feb. 1994, pp. 388-395. 